\title{
A modelled economic evaluation comparing atomoxetine with methylphenidate in the treatment of children with attention-deficit/hyperactivity disorder in Spain Jihyung Hong*1,2, Tatiana Dilla ${ }^{3}$ and Jorge Arellano ${ }^{2}$
}

Address: ${ }^{1}$ LSE Health, London School of Economics, London, UK, ${ }^{2}$ Eli Lilly and Company, Windlesham, UK and ${ }^{3}$ Eli Lilly and Company, S.A, Alcobendas (Madrid), Spain

Email: Jihyung Hong* - j.hong@lse.ac.uk; Tatiana Dilla - dilla_tatiana@lilly.com; Jorge Arellano - arellano_jorge@lilly.com

* Corresponding author

Published: 14 April 2009

BMC Psychiatry 2009, 9:15 doi:10.1186/147I-244X-9-15
Received: 30 August 2008

Accepted: 14 April 2009

This article is available from: http://www.biomedcentral.com/147/-244X/9/15

(C) 2009 Hong et al; licensee BioMed Central Ltd.

This is an Open Access article distributed under the terms of the Creative Commons Attribution License (http://creativecommons.org/licenses/by/2.0), which permits unrestricted use, distribution, and reproduction in any medium, provided the original work is properly cited.

\begin{abstract}
Background: Attention Deficit/Hyperactivity Disorder (ADHD) is a neurobehavioural disorder, affecting 3-6\% of school age children and adolescents in Spain. Methylphenidate (MPH), a mild stimulant, had long been the only approved medication available for ADHD children in Spain. Atomoxetine is a non-stimulant alternative in the treatment of ADHD with once-a-day oral dosing. This study aims to estimate the cost-effectiveness of atomoxetine compared to MPH. In addition, atomoxetine is compared to 'no medication' for patient populations who are ineligible for MPH (i.e. having stimulant-failure experience or co-morbidities precluding stimulant medication).
\end{abstract}

Methods: An economic model with Markov processes was developed to estimate the costs and benefits of atomoxetine versus either MPH or 'no medication'. The incremental cost per qualityadjusted life-year (QALY) was calculated for atomoxetine relative to the comparators. The Markov process incorporated 14 health states, representing a range of outcomes associated with treatment options. Utility values were obtained from the utility valuation survey of 83 parents of children with ADHD. The clinical data were based on a thorough review of controlled clinical trials and other clinical literature, and validated by international experts. Costs and outcomes were estimated using Monte Carlo simulation over a I-year duration, with costs estimated from the perspective of the National Health Service in Spain.

Results: For stimulant-naïve patients without contra-indications to stimulants, the incremental costs per QALY gained for atomoxetine were $€ 34308$ (compared to an immediate-release MPH) and $€ 24310$ (compared to an extended-release MPH). For those patients who have stimulantfailure experience or contra-indications to stimulants, the incremental costs per QALY gained of atomoxetine compared to 'no medication' were $€ 23820$ and $€ 23323$, respectively.

Conclusion: The economic evaluation showed that atomoxetine is an effective alternative across a range of $A D H D$ populations and offers value-for money in the treatment of ADHD. 


\section{Background}

Attention Deficit/Hyperactivity Disorder (ADHD) is a neurobehavioural disorder and one of the most prevalent chronic health problems affecting school-age children [1], representing a costly major public health problem [2]. It begins early in childhood and persists throughout adolescence and well into adulthood in the majority of cases $[3,4]$. Affected children commonly exhibit disruptive behaviour in the classroom, underachieve academically and tend to have conflictive relations with family members and peers [5]. ADHD is also frequently associated with co-morbidities such as learning disorders, tics, anxiety and conduct disorders [6-8]. Without effective treatments, difficulties associated with the disorder may have long-term negative consequences such as difficulties in employment or in forming a good relationship, as well as the risk of substance abuse, crime and accidental injury [914]. In Spain, the estimated prevalence of ADHD among school-aged children is around 3-6\% [15-17]

Multi-disciplinary approach to the management of ADHD is often suggested, in which medication may be an integral part when remedial measures alone prove insufficient [18]. In Spain, medications licensed for the treatment of ADHD include methylphenidate hydrochloride (MPH) and atomoxetine. $\mathrm{MPH}$, which is mainly available as either immediate-release (IR) or an extended-release (XR) formulation, has been by far the most widely used medication for ADHD worldwide. Given that MPH is a stimulant medication however, it may have abuse risk or produce variations in mood state, sleep disorder or increase in tic severity [19]. MPH is thus contraindicated in patients with severe depression, marked anxiety, tics, a family history or diagnosis of Tourette's syndrome, known drug dependence or a history of drug dependence or alcoholism [20]. Treatment guidelines for some of these contra-indications may have not been followed strictly in the past due to the lack of alternative medication options. Atomoxetine, newly introduced in the Spanish market, is an alternative to stimulants in the treatment of ADHD with once-a-day oral dosing [20]. There is consistent evidence that atomoxetine is superior to placebo while no clear differences have been found between atomoxetine and MPH on the grounds of clinical efficacy in terms of standard measures of ADHD symptom control [21] though there has been increasing evidence in favour of MPH [22]. However, atomoxetine may have longer lasting effects compared to MPH. Results of a placebocontrolled trial suggests that, among those patients who respond to atomoxetine, a single dose each morning provides a lasting effect through to the following morning, provided that the medication is taken on a regular daily basis [23]. In contrast, the duration of efficacy of MPH may be more limited. A single dose of XR-MPH, or three repeated doses of IR-MPH, would provide about 12 hours of therapeutic coverage [24-26]. In view of their pharmacokinetic and pharmacodynamic characteristics as well as usual dose regimens, it is as such unlikely that these drugs would provide therapeutic coverage through the night or at the time of waking.

The objective of the present study was to estimate the costeffectiveness of atomoxetine compared to $\mathrm{MPH}$ in the treatment of children with ADHD. As atomoxetine may offer a viable alternative for a substantial proportion of ADHD children who were ineligible for MPH due to a history of stimulant treatment failure and/or co-morbidities contra-indicated to simulants, atomoxetine treatment for these children was also compared to 'no medication' since they would usually have no alternative medication options otherwise. The present economic model adapted the UK model [27] and was modified to compare the costs and benefits of atomoxetine to that of either MPH or 'no medication' in the Spanish context.

\section{Methods}

\section{Patient population}

In recognition that i) children with ADHD are frequently co-diagnosed with one or more co-morbidities [28] some of which are contra-indicated for medication with stimulants [29] and ii) a patient's past stimulant history is a determining factor in clinical outcomes [30,31], patients in the evaluation are segmented into three mutually exclusive patient groups, according to history of stimulant treatment failure and contra-indication status.

- Stimulant-naïve patients without contra-indications to stimulants (population 1): These are patients with no history of pharmacotherapy use and no contraindications to stimulants

- Stimulant-failed patients without contra-indications to stimulants (population 2): These are patients who have previously (prior to entry into the model) been medicated with MPH but have failed due to lack of efficacy or intolerable side effects

- Stimulant-naïve patients with contra-indications to stimulants (population 3): These patients have no history of pharmacotherapy use but are precluded from using stimulant therapies due to a pre-existing contraindicated condition(s) - including severe depression, marked anxiety, tics, a family history or diagnosis of Tourette's syndrome, known drug dependence or a history of drug dependence or alcoholism [29]

Patients who were currently successfully being treated with MPH were excluded from the analysis because it was assumed that these patients were unlikely to switch medication. 


\section{Treatments and comparators}

The approach used to calculate the cost-effectiveness of atomoxetine is based on current treatment available to each of the patient groups hence reflecting the likely impact on cost and outcomes in real practice for each of them.

Atomoxetine was compared to MPH (IR-MPH and XR-MPH respectively) as a first-line therapy in population 1. Patients could switch from atomoxetine to MPH and vice versa as a second-line treatment when the first-line treatment failed. Subsequently they could stop all therapies upon failure of second-line therapy and remain on 'no medication' until the end of the model. For those patient groups (population 2 and 3) who are ineligible for MPH treatment, atomoxetine was compared to 'no medication'. Patients treated with atomoxetine could discontinue the medication upon failure of therapy and remain un-medicated until the end of the model while patients in the 'no medication' arm would remain unmedicated throughout the model.

\section{Model structure}

The UK economic model [27] was adapted and re-constructed using TreeAge Pro software [32] to calculate and compare the costs and benefits of atomoxetine to that of either MPH or 'no medication' in the Spanish context. The economic evaluation employed a cost-utility analysis to calculate the incremental cost per quality-adjusted lifeyear (QALY) gained by atomoxetine compared with the treatment options available in Spain.

The model employed a Monte Carlo simulation, whereby a single patient was followed through the Markov process in monthly cycles over a period of one year. It was deemed inappropriate to extend the model beyond the timeframe covered by the available clinical data. Instead, it was implicitly assumed that there are no differences in health benefits between the medications in the longer term. Costs and outcomes were accumulated as the patient advanced through the cycles and 20,000 simulations were performed for each patient population to establish the mean costs and outcomes across all possible transitions through the Markov process. These results were then used to calculate incremental cost-effectiveness ratios for each comparison in the different patient populations. Given that the model duration was one year, costs and effects were not discounted. The Markov process employed a half cycle correction which meant that patients were attributed their initial health state utility values half way through the first cycle [33].

The Markov process comprised fourteen and six health states for population 1 and for population 2 and 3, respectively. Each health state represented one of a range of possible health outcomes (response and/or occurrence of adverse events) associated with treatment alternatives considered in the economic model. Upon entering the Markov process, patients were distributed into one of four health states associated with atomoxetine or those associated with either MPH (in population 1) or 'no medication (in population 2 and 3). Upon failure of therapy, patients could move through to health states associated with the next treatment options (see Figure 1).

Patients could remain within their resident health state until one of the following events occurred

- The patient discontinues medication due to lack of efficacy: applicable only to patients on an active treatment and in a non-responder health state. The model assumes a maximum of two consecutive non-response cycles. A third non-response cycle results in automatic discontinuation due to lack of efficacy. After discontinuing one medication, the patient will switch immediately to the next alternative in the treatment algorithm to being the next Markov cycle.

- The patient discontinues medication due to a medication-related adverse event and progresses to the next line of therapy.

- An adverse event resolves

- The patient discontinues medication for any other reason: applicable equally to all patients on active treatment. These patients are assumed to stop therapy altogether.

- The patient relapses: applicable only to those patients in a responder health state. A patient who relapses becomes a non-responder in the following Markov cycle.

\section{Model variables}

Costs

Costs were estimated from the perspective of the National Health Service in Spain. The economic model considered only the pharmaceutical cost of treatment when comparing medication alternatives, thereby assuming that all non-drug health care costs and indirect costs were equivalent between the treatment groups being compared.

Such an assumption may be considered biased against the active therapies which have the potential to reduce symptoms and consequently, a patient's reliance on health care professionals. Furthermore, the cost of drugs associated with the treatment of medication-related side effects was not considered. Due to the persistence of insomnia, patients treated with stimulant (i.e. $\mathrm{MPH}$ ) are more likely than patients treated with atomoxetine to require concomitant medications for side effects, indicating that the exclusion of these costs may be biased against atomoxetine.

Cost variables used in the Markov process are presented in Table 1. Most patients with atomoxetine need only a sin- 


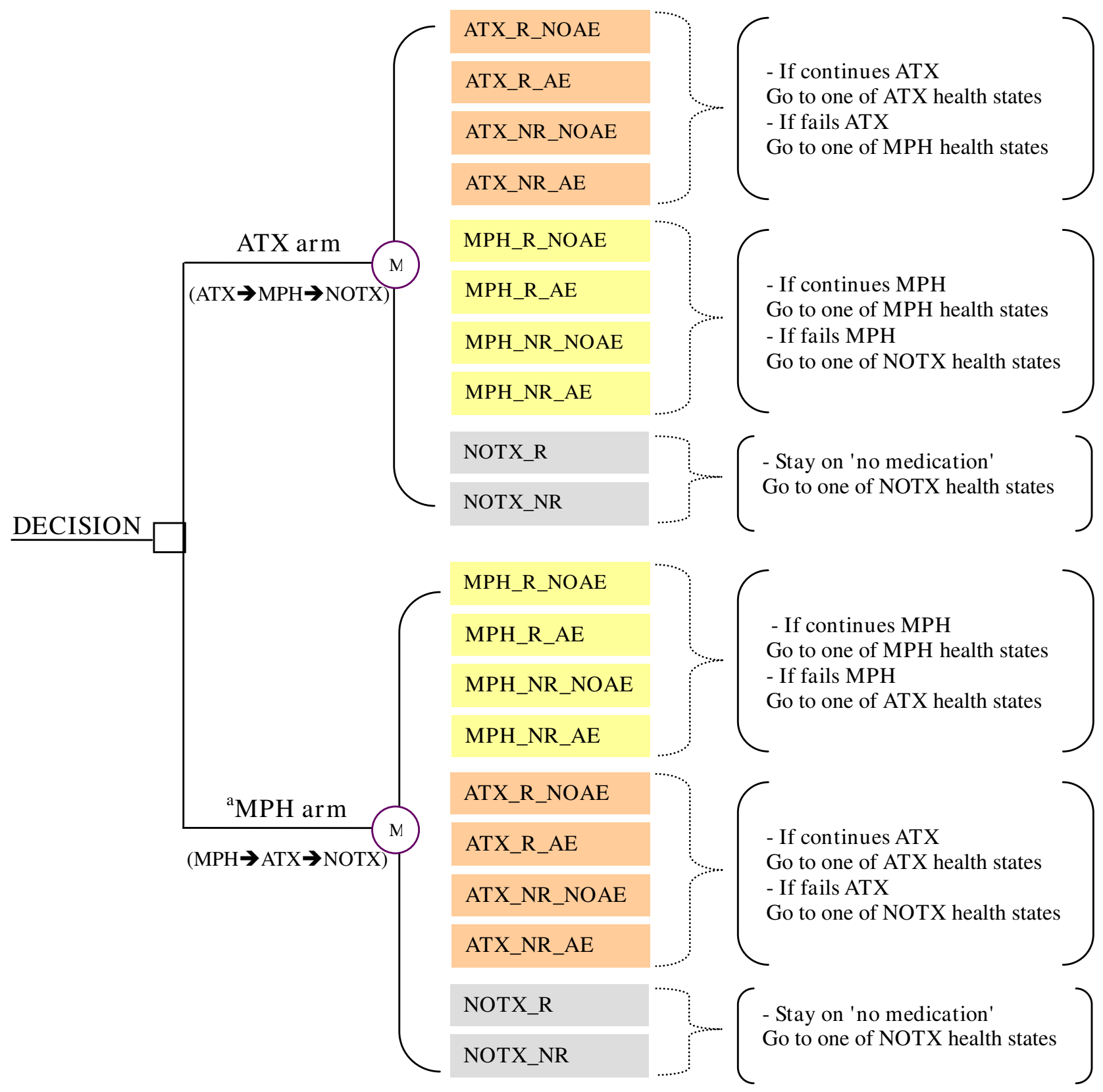

\section{Figure I}

Structure of the Markov process in population I. Abbreviation: $\mathrm{ATX}=$ atomoxetine; $\mathrm{MPH}=$ methylphenidate; $\mathrm{NOTX}=$ no medication; $R=$ response; $N R=$ no response; $A E=$ adverse events; $N O A E=$ no adverse events. ${ }^{\text {a Either } I R-M P H}$ or $X R-$ $\mathrm{MPH}$ is separately compared to atomoxetine. *Note: The Markov model is similarly structured even when atomoxetine is compared to 'no medication' for those who are ineligible for MPH treatment. In this case, all health states related to MPH are eliminated from the current model.

gle capsule per day and a single capsule costs $€ 4.34$, irrespective of capsule strength. Thus $€ 4.34$ was used in the model as the daily cost of atomoxetine. Calculation of the daily cost of MPH was based on the estimated average daily dose taken by patients and the relative use of available pack sizes for each medication according to current market research [34-36]. Unit costs of MPH were derived from data available at the General Spanish Council of Pharmacists (CGCOF) [34-36]. Patients in the model received 30 days of medication per montly cycle.

\section{Health state utility values}

Health state utility values for the fourteen possible health states included in the economic model were based on a 
Table I: Medication costs in the economic model

\begin{tabular}{|c|c|c|c|}
\hline & Atomoxetine cost & IR-MPH cost & XR-MPH cost \\
\hline Average daily dose & I capsule & $43.11^{\mathrm{a}}$ & $43.43^{\mathrm{a}}$ \\
\hline Daily cost of medication & $€ 4.34 \mathrm{~b}$ & $€ 0.48 \mathrm{c}$ & $€ 2.63 c$ \\
\hline Days on medication per Markov cycle & 30 & 30 & 30 \\
\hline Cost of medication per Markov cycle & 130.20 & 14.40 & 78.90 \\
\hline
\end{tabular}

Abbreviations: IR-MPH = immediate-release methylphenidate; $\mathrm{XR}-\mathrm{MPH}=$ extended-release methylphenidate

a. Market research data [34-36]

b. Daily cost of atomoxetine is independent of average daily dose. Cost is based on a cost per capsule, independent of capsule strength [34-36]

c. Daily costs of IR-MPH and XR-MPH based on current costs applied to the average daily dose, weighted by the relative days of therapy of each pack size for each medication [34-36]

utility valuation survey of 83 parents of children with ADHD in the UK using standard gamble methodology [37]. Parents were chosen as the most suitable patient proxy respondents on the basis that many ADHD children would be too young to provide reliable responses.

The health state description comprised four domains: 1) descriptors referring to behaviour during different time periods throughout the day; 2) information concerning the child's overall social well-being; 3 ) attributes regarding medication regimen (e.g. frequency of adminitration); 4) medication-related adverse events. Descriptions for the four domains were derived largely based on systematic review of clinical trials and validated by clinical experts. Further details of the descriptors for the fourteen health states in terms of the four domains can be found elsewhere [37].

The health state corresponding to the atomoxetine 'responder without side effects' had the highest utility value (0.959). Health states corresponding to 'responder without side effects' for XR-MPH and IR-MPH had utility values of 0.930 and 0.913 , respectively. The higher utility scores associated with atomoxetine responders are mainly attributable to its better behavioural profiles. Atomoxetine responder health states reflects improved behaviour in the early morning as well as at night [23], whereas stimulant responder health states reflects only for a limited time following administration of medication. For each of the 'no medication' health states, utility values of 0.880 were obtained from the 'child's own health state' as given by a subgroup of 23 parents whose children were not currently receiving medication. Table 2 presents the utiltity scores incorporated in the economic model.

\section{Transition probabilities}

Transition probabilities used to populate the Markov process and respective data sources are presented in Table 3 and 4. Note that some are data on file and the details of the sources can be found in the UK model paper [27]. In addition, clinical trials directly included in this study for the data synthesis were approved according to local requirements for ethics and/or regulatory approvals for clinical trials.
Probabilities that did not vary by patient population (Table 3), including probabilities of medication related adverse events and discontinuations from treatment, were derived from placebo-controlled clinical trials for atomoxetine [38-42] (some are data on file) and a published indirect meta-analysis of safety data from randomised placebo-controlled and active comparator studies of atomoxetine and methylphenidate [43].

Medication-related adverse events were defined as any adverse event (i) found to be significant for atomoxetine in a pooled analysis of safety data from six pivotal randomised placebo-controlled trials [38-40,42] (some are data on file) (ii) found to be significant for IR-MPH in a publised quantitative meta-analysis of safety data from randomised controlled trials [44] or (iii) listed as very common (frequency $\geq 10 \%$ ) for IR-MPH and/or XR-MPH in Summary Product Characteristics [29]. Medicationrelated adverse events comprised appetite loss, stomach ache, vomiting, somnolence, irritability, dizziness, fatigue, insomnia, headache and nervousness.

Assumptions regarding the persistence of medicationrelated adverse events were based on long-term treatment data for atomoxetine (data on file), where weekly reports of adverse events, either as a first or repeat occurrence, fell off with time to fairly constant low levels which, in many cases, were considered to be close to the baseline reporting of such adverse events. These data implied that for most patients medication-related side effects mainly occured early on in the treatment and were likely to resolve within approximately 16 weeks.

Data concerning time to resolution for MPH-related adverse events were not available. Since adverse events associated with MPH were mostly considered mild and transient, the model assumed that, with one exception, the time to resolution for MPH-related adverse events was the same as for atomoxetine. The exception to this was stimulant-associated insomnia, which could persist in a proportion of cases. The probability that medicationrelated insomnia persists in MPH-treated patients was 
Table 2: Utility values derived from the utility valuation survey [37]

\begin{tabular}{|c|c|c|c|c|}
\hline Health State & $\mathbf{N}$ & Mean utility value & SD & $95 \% \mathrm{Cl}$ \\
\hline Medication with atomoxetine; responder without side effects & 83 & 0.959 & 0.077 & $0.942-0.976$ \\
\hline Medication with atomoxetine; responder with side effects & 83 & 0.937 & 0.096 & $0.916-0.958$ \\
\hline Medication with atomoxetine; non-responder without side effects & 83 & 0.902 & 0.133 & $0.873-0.931$ \\
\hline Medication with atomoxetine; responder with side effects & 83 & 0.886 & 0.148 & $0.854-0.918$ \\
\hline Medication with IR-MPH; responder without side effects & 83 & 0.913 & 0.128 & $0.885-0.941$ \\
\hline Medication with IR-MPH; responder with side effects & 83 & 0.904 & 0.137 & $0.875-0.933$ \\
\hline Medication with IR-MPH; non-responder without side effects & 83 & 0.889 & 0.154 & $0.856-0.922$ \\
\hline Medication with IR-MPH; responder with side effects & 83 & 0.875 & 0.164 & $0.840-0.910$ \\
\hline Medication with XR-MPH; responder without side effects & 83 & 0.930 & 0.107 & $0.907-0.953$ \\
\hline Medication with XR-MPH; responder with side effects & 83 & 0.912 & 0.124 & $0.885-0.939$ \\
\hline Medication with XR-MPH; non-responder without side effects & 83 & 0.898 & 0.130 & $0.870-0.926$ \\
\hline Medication with XR-MPH; responder with side effects & 83 & 0.884 & 0.143 & $0.853-0.915$ \\
\hline No medication; responder & 23 & 0.880 & 0.133 & $0.826-0.934$ \\
\hline No medication; non-responder & 23 & 0.880 & 0.133 & $0.826-0.934$ \\
\hline
\end{tabular}

Abbreviations: IR-MPH = immediate-release methylphenidate; $\mathrm{XR}-\mathrm{MPH}=$ extended-release methylphenidate; $\mathrm{SD}=$ standard deviation

based on responses collected in a survey of consultant child and adolesent pscyhiatrists, all highly experienced in treating children with ADHD (data on file).

Probabilities of response and relapse varied by patient population (Table 4). The evidence base for these variables in each of the populations are described below.

\section{Population I}

Probabilities of treatment response in patients with no history of pharmacotherapy use and no contra-indications to stimulants were derived from responder rates estimated in a meta-regression analysis [45] of patient-level data from five randomised active comparator trials of atomoxetine and MPH $[39,46,47]$ (some are data on file).

\section{Population 2}

Probabilities of response to atomoxetine in patients with a previous MPH treatment failure but no contra-indications to stimulants were derived and inferred from responder rate in the patients treated with atomoxetine after a failure of an initial 6 weeks treatment with XR-MPH in a randomised cross-over study of XR-MPH and atomoxetine [47]. A probability of response on 'no medication' in this population was derived by applying the relative risk of response for placebo versus atomoxetine, drawn from the meta-regression analysis [45].

\section{Population 3}

The probability of treatment response in patients with no history of pharmacotherapy use and contra-indications to stimulants was derived from responder rate in patients with no history of pharmacotherapy use in a randomised placebo-controlled trial of atomoxetine conducted exclusively in an ADHD patient group who had been co-diagnosed with tic disorder or Tourette's syndrome [41]. The limitation of this, of course, is that patients with tics or Tourette's syndrome constitute a subgroup of, rather than being representative of, the overall stimulant-contraindicated population. However, in the absence of data from a more appropriate patient group, this is best estimate available.

Probabilities of relapse were based on data for stimulantnaïve and stimulant-exposed patients in a placebo-controlled relapse prevention trial of atomoxetine responders [48]. In the absence of comparative data, an assumption of parity was made between relapse rates for all active 
Table 3: Transition probabilities used in the Markov process that do not vary by patient population

\begin{tabular}{|c|c|c|c|c|c|}
\hline & & \multicolumn{3}{|c|}{ Probability by treatment } & \multirow[b]{2}{*}{ No medication } \\
\hline & & Atomoxetine & IR-MPH & XR-MPH & \\
\hline $\begin{array}{l}\text { Probability of one or more medication-related } \\
\text { adverse events }\end{array}$ & & 0.129 & 0.129 & 0.129 & 0.000 \\
\hline $\begin{array}{l}\text { Probability that a medication-related adverse } \\
\text { event is insomniab }\end{array}$ & & 0.000 & 0.48 & 0.48 & NA \\
\hline \multirow{2}{*}{$\begin{array}{l}\text { Probability that a medication-related adverse } \\
\text { event, which is not insomniac }\end{array}$} & First 4 cycles & 0.473 & 0.473 & 0.473 & NA \\
\hline & Cycles thereafter & 1.000 & 1.000 & 1.000 & NA \\
\hline \multirow{2}{*}{$\begin{array}{l}\text { Probability that insomnia will persist from one } \\
\text { Markov cycle to the next }\end{array}$} & First 4 cycles & NA & 0.953 & 0.953 & NA \\
\hline & Cycles thereafter & NA & 1.000 & 1.000 & NA \\
\hline $\begin{array}{l}\text { Probability that a non-responder discontinues } \\
\text { due to lack of efficacy during a Markov cycle }\end{array}$ & & 0.0989 & 0.0989 & 0.0989 & NA \\
\hline $\begin{array}{l}\text { Probability that a patient discontinue due to a } \\
\text { medication-related adverse event during a } \\
\text { Markov cycle }\end{array}$ & & 0.1209 & 0.1209 & 0.1209 & NA \\
\hline \multirow{2}{*}{$\begin{array}{l}\text { Probability that a patient discontinues for } \\
\text { reasons other than lack of efficacy or a } \\
\text { medication-related adverse event during a } \\
\text { Markov cycle }\end{array}$} & First 4 cycles & 0.384 & 0.384 & 0.384 & NA \\
\hline & Cycles thereafter & 0.000 & 0.000 & 0.000 & NA \\
\hline
\end{tabular}

Abbreviations: IR-MPH = immediate-release methylphenidate; $X \mathrm{R}-\mathrm{MPH}=$ extended-release methylphenidate; $N A$ = Not applicable

a. Probabilities based on post hoc analyses of safety data pooled from six randomised placebo-controlled trials of atomoxetine versus placebo [3840,42] (some are data on file). Assumption of parity between active treatments based on similar post hoc analyses of data from a limited open-label direct comparator study [46], supported by data from a double-blind randomised trial of atomoxetine and XR-MPH (data on file) where the proportions of patients experiencing one or more adverse events of any nature were not significantly different between the active treatments. Values are net of the placebo rate, meaning that the 'no medication' probability is zero, by definition.

b. The probability based on the relative risk (0.4I7) of insomnia (atomoxetine vs IR-MPH), estimated in an indirect meta-analysis of safety data [43], applied to the risk of insomnia for atomoxetine $(4.7 \%)$ derived from pooled analysis of safety data from six pivotal randomised placebo-controlled trials of atomoxetine [38-40,42] (some are data on file), giving a rate of insomnia for IR-MPH of 4.7/0.4I7 = II.27\%. The model assumes that insomnia is experienced only as a result of taking medication. Therefore, the probability for placebo is not applicable (i.e. zero) and the probabilities for active treatments are net of the placebo rate (i.e. subtract $5.1 \%$ ). As a consequence, the model assumes that patients on atomoxetine have no risk of medication-related insomnia. Patients on IR-MPH who experience insomnia will come only from the population who experience one or more adverse events as derived in note I, therefore, for 'if adverse event, probability that insomnia included' $=(I I .27-5 . I) / I 2.9=48 \%$. Parity is assumed between IR-MPH and XR-MPH [24,26].

c. Probabilities based on temporal course of treatment-emergent adverse events (data on file) where weekly reports from patients treated with atomoxetine over 52 weeks imply that, for most patients, medication-related averse events mainly occur early in the treatment and are likely to resolve within approximately 16 weeks. The probability of $0.473\left(0.05^{1 / 4}\right)$ for the first four cycles with adverse event(s) reflects a nominal $5 \%$ of patients in whom adverse events (that are not insomnia) persists over this duration of the Markov process. The duration of persistence of adverse events (that are not insomnia) is assumed to be similar for each medication.

d. Probabilities based on a survey of six consultant child and adolescent psychiatrists (data on file). Responses suggested that $82.5 \%$ of cases of stimulant-related insomnia would persist for more than 16 weeks. The model assumes that patients with stimulant-related insomnia that persists beyond four cycles will continue to have insomnia as long as they remain on treatment. The probabilities of $0.953\left(0.824^{1 / 4}\right)$ for the first four cycles of the Markov process and 1.000 for cycles thereafter reflect this.

e. Probabilities based on discontinuation rates, regardless of treatment, from data pooled from seven randomised placebo-controlled trials of atomoxetine [38-42] (some are data on file), adjusted for differences between trials with respect to duration of follow-up. Discontinuations due to lack of efficacy were assumed to occur in only the non-responder population. In each case, parity is assumed between the active treatments. f. Probabilities based on discontinuation rates due to adverse events from data pooled from six pivotal randomised placebo-controlled trials of atomoxetine [38-40,42] (some are data on file), adjusted for differences between trials with respect to duration of follow-up. Discontinuations due to adverse events were assumed to occur only in the population experiencing one or more medication-related adverse events and therefore were net of the placebo rate. In each case, parity is assumed between the active treatments. 
Table 4: Transition probabilities used in the Markov process that vary by patient population

\begin{tabular}{|c|c|c|c|c|c|}
\hline & \multirow[b]{2}{*}{ Population } & \multicolumn{3}{|c|}{ Probability by treatment } & \multirow[b]{2}{*}{ No medication } \\
\hline & & Atomoxetine & IR-MPH & XR-MPH & \\
\hline \multirow[t]{3}{*}{$\begin{array}{l}\text { Probability of response to } \\
\text { treatment }\end{array}$} & $\begin{array}{l}\text { I. Stimulant-naïve, not contra- } \\
\text { indicated }^{a}\end{array}$ & 0.7051 & 0.7727 & 0.7727 & NA \\
\hline & $\begin{array}{l}\text { 2. Stimulant-failed, not contra- } \\
\text { indicated }^{\mathrm{b}}\end{array}$ & 0.6346 & NA & NA & 0.3731 \\
\hline & $\begin{array}{l}\text { 3. Stimulant-naïve, contra- } \\
\text { indicatedc }\end{array}$ & 0.6667 & NA & NA & 0.423 \\
\hline \multirow[t]{3}{*}{$\begin{array}{l}\text { Probability of relapse per } 30 \text { - } \\
\text { day periodd }\end{array}$} & $\begin{array}{l}\text { I. Stimulant-naïve, non contra- } \\
\text { indicated }\end{array}$ & 0.0206 & 0.0206 & 0.0206 & NA \\
\hline & $\begin{array}{l}\text { 2. Stimulant-failed, non contra- } \\
\text { indicated }\end{array}$ & 0.0257 & NA & NA & 0.0447 \\
\hline & $\begin{array}{l}\text { 3. Stimulant-naïve, contra- } \\
\text { indicated }\end{array}$ & 0.0206 & NA & NA & 0.0387 \\
\hline
\end{tabular}

Abbreviations: IR-MPH = immediate-release methylphenidate; $\mathrm{XR}-\mathrm{MPH}=$ extended-release methylphenidate; $\mathrm{NA}=$ not applicable

a. Probabilities of response in stimulant-naïve patients are not contra-indicated are based on a meta-regression analysis [45] of response data from randomised active comparator trials of atomoxetine and $\mathrm{MPH}[39,46,47]$ (some are data on file). Assumption of parity between stimulants is based on head-to-head trials of IR-MPH and XR-MPH [24,26].

b. Probabilities of response in MPH-exposed (failed) patients in whom stimulants are not contra-indicated are derived and inferred from responder rates in a crossover trial of atomoxetine and XR-MPH [47]. A probability of response for 'no medication' is derived by applying the relative risk of repsonse for placebo versus atomxetine, drawn from the meta-regression analysis [45].

c. Probabilities of response in stimulant-naïve patients in whom stimulants are contra-indicated are based on responder rates from a randomised placebo-controlled trial of atomoxetine in patients with tics or Tourette's syndrome [4I].

d. Probability of relapse $=\mathrm{I}-\left[(\mathrm{I}-\mathrm{C})^{(\mathrm{I} / \mathrm{E})}\right]$, where $\mathrm{C}=$ the proportion of patients relapsing and $\mathrm{E}=$ approximate total number of follow-up days, derived from a relapse prevention study [48], divided by the approximate number of days per Markov cycle. Parity is assumed between active medications.

Table 5: Total costs, QALYs and incremental cost-effectiveness estimated in the economic model by patient population

\begin{tabular}{lccccc}
\hline Population & $\begin{array}{c}\text { Cost per patient } \\
\text { ATX arm }\end{array}$ & $\begin{array}{c}\text { Comparator arm } \\
\text { ATX }\end{array}$ & $\begin{array}{c}\text { QALYs per patient } \\
\text { ATX arm }\end{array}$ & $\begin{array}{c}\text { Comparator arm } \\
\text { QALY gained }\end{array}$ \\
\hline $\begin{array}{l}\text { Population Ia } \\
\text { (comparator: IR-MPH) }\end{array}$ & $€$ I 047 & $€ 366$ & 0.930 & 0.910 & $€ 34308$ \\
$\begin{array}{l}\text { Population Ia } \\
\text { (comparator: XR-MPH) }\end{array}$ & $€$ I 208 & $€ 902$ & 0.933 & 0.920 & $€ 24310$ \\
$\begin{array}{l}\text { Population 2b } \\
\text { (comparator: 'no medi- } \\
\text { cation') }\end{array}$ & $€ 919$ & $€ 0$ & 0.919 & 0.880 & $€ 23820$ \\
$\begin{array}{l}\text { Population 3c } \\
\text { (comparator: 'no medi- } \\
\text { cation') }\end{array}$ & $€ 969$ & $€ 0$ & 0.922 & 0.880 & $€ 23323$ \\
\hline
\end{tabular}

Abbreviations: ATX = atomoxetine; IR-MPH = immediate-release methylphenidate; XR-MPH = extended-release methylphenidate; QALY = Qualityadjusted life year

a. Stimulant-naïve patients without contra-indications to stimulants

b. Stimulant-failed patients without contra-indications to stimulants

c. Stimulant-naïve patients with contra-indications to stimulants

treatments and also between patients who were contraindicated for stimulants and those who were not.

For all transition probability variables, where applicable, the assumption of parity between IR-MPH and XR-MPH was made based on data published from head-to-head trials of treatments [24,26].

\section{Sensivity analysis}

Extensive sensivity analyses were carried out on cost, utility and transition probability variables.

\section{Results}

The results of the economic model are summarised in Table 5. Overall, treatment with atomoxetine was associ- 
ated with higher costs and better health outcomes, translated into increased QALYs, when compared to either MPH (both IR-MPH and XR-MPH) or 'no medication'.

For the stimulant-naïve patients without contra-indications to stimulants (population 1), treatment with atomoxetine was associated with additional costs of $€ 681$ compared to IR-MPH and $€ 306$ compared to XR-MPH. For the patients having stimulant-failure experience or contra-indications to stimulants (population 2 and 3), atomoxetine was in principle the only alternative option available. Atomoxetine was thus compared to 'no medication' within these groups of patients. The additional cost of atomoxetine treatment compared to 'no medication' was $€ 919$ in the stimulant-failed patients without contraindications to stimulants (population 2). Similar cost ( $€$ 969) was incurred as well by atomoxetine treatment in the stimulant-naïve patients but having contra-indications to stimulants (population 3).

Patients who started treatment with atomoxetine experienced slightly less time with adverse events than patients with MPH in population 1, while the duration of response over the 1-year period was similar between the two groups (results not shown). This, together with the higher utility value associated with a response to atomoxetine relative to the MPH or 'no medication', translated into QALY gains for patients treated with atomoxetine. For the stimulant-naïve patients without contra-indications to stimulants (population 1), treatment with atomoxetine was associated with 0.020 and 0.013 additional QALYs gained, when compared to IR-MPH and XR-MPH, respectively. The magnitude of additional QALYs gained associated with atomoxetine, was greater among the patients having stimulant-failure experience or contra-indications to stimulants (population 2 and 3 ) as 'no medication' (i.e. comparator of atomoxetine in these patient populations) was associated with the lowest utility values of 0.880 . The additional QALYs gained associated with atomoxetine treatment was 0.039 and 0.042 in population 2 and 3 , respectively.

The incremental cost per QALY gained associated with atomoxetine was consistently lower among the patients having stimulant-failure experience or contra-indications to stimulants (population 2 and 3), in comparison to that of the stimulant naïve patients without contra-indications to stimulant (population 1). The incremental cost per QALY gained of atomoxetine was $€ 23820$ and $€ 23323$ in population 2 and 3 respectively while it was $€ 34308$ and $€ 24310$ compared to IR-MPH and XR-MPH respectively in population 1 . This is an intuitive result because atomoxetine is the most cost-effective in the patient group in which there are no pharmacotherapy alternatives currently available (i.e. in population 2 and 3 ) and least cost- effective in the treatment naïve patient group for which other pharmacotherapy options are available (i.e. population 1).

In addition, an extensive range of one-way and scenariobased sensitivity analyses were performed for other uncertain model variables and assumptions. In general, the incremental cost per QALY gained in each population was insensitive to changes in key clinical and cost variables (results not shown; the full results of sensitivity analyses are available from the authors upon request). However, the sensitivity analyses show that the utility values of all health states are crucial determinants of the cost-effectiveness of atomoxetine.

Given the importance of the utility values to the results of the economic model, additional sensitivity analyses of the utility values were explored for the stimulant-naïve patients without contra-indications to stimulants (population 1), in which both atomoxetine and $\mathrm{MPH}$ were possible treatment options. The additional analysis was to see how the results of the model are affected when differences between utility values of corresponding health states of atomoxetine and those of MPH (either IR-MPH or XR$\mathrm{MPH}$ ) are reduced or eliminated.

The incremental cost per QALY gained associated with atomoxetine was $€ 34308$ (compared to IR-MPH) and $€$ 24310 (compared to XR-MPH) for the base case analysis. When differences in the utility values between corresponding health states of different treatments were reduced by $25 \%$ by increasing the base case utility values of MPH, the incremental cost per QALY gained became $€$ 48643 and $€ 30685$ (see Figure 2). It again increased to $€ 68101$ and $€ 43835$ when differences in utility values were reduced by $50 \%$. Finally, when differences in utility values are eliminated (i.e. 100\% reduction), the incremental cost per QALY ratios went up dramatically.

This sensitivity analysis shows that when differences in utility values between treatment groups are removed the incremental cost per QALY gained of atomoxetine rises to unacceptable levels. However, the modest increase in the cost per QALY when differences are reduced by up to $50 \%$ and the sound methodology used to derived the utility values [32] serves to minimise the uncertainty surrounding the utility values and thus maximise the reliability of the base case model results.

\section{Discussion}

This study sought to apply pharmacoeconomic modelling techniques to the process of informing the selection of a cost effective treatment for children with ADHD in Spain. Atomoxetine, a newly introduced treatment option in the Spanish market, was compared to methylphenidate, which had been 


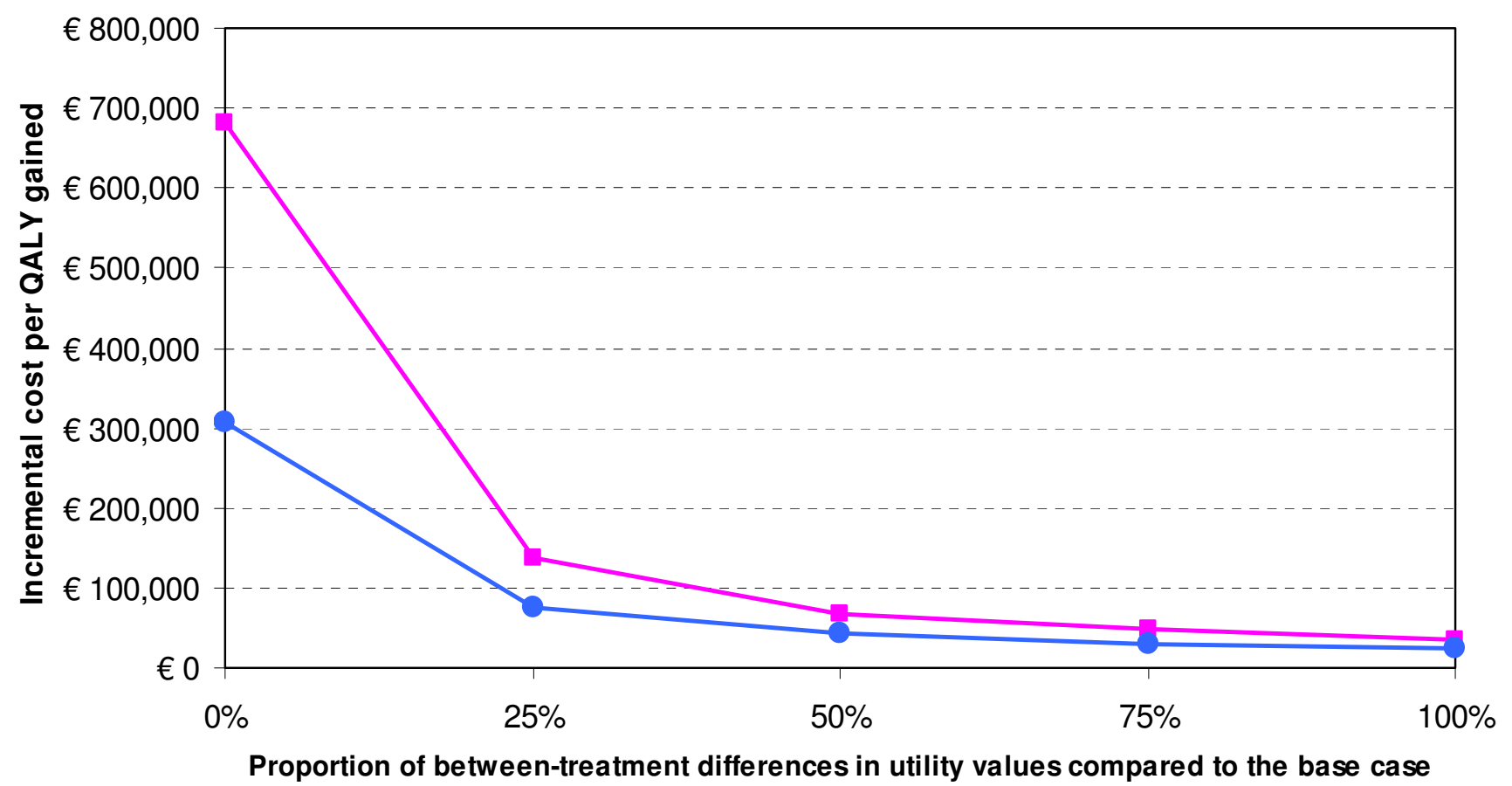

$\rightarrow$ Atomoxetine vs IR-MPH $\multimap-$ Atomoxetine vs XR-MPH

\section{Figure 2}

The ICERs of atomoxetine under varying utility values used in the model in population I. Abbreviations: IR-MPH = immediate-release methylphenidate; XR-MPH = extended-release methylphenidate; QALY = Quality of life years.

the only approved medication available for ADHD children in Spain. In addition, atomoxetine was compared to 'no medication' among those who were ineligible for methylphenidate treatment (i.e. patients having a history of stimulant-treatment failure or co-morbidities contra-indicated to stimulants). The results of the economic model showed that atomoxetine is associated with better outcomes in terms of QALYs over a 1-year time horizon, compared to methylphenidate (both IR-MPH and XR-MPH) as well as 'no medication'. Although response rate was found to be equal or higher for methylphenidate, patients responding to atomoxetine appeared to experience a more stable and longer-lasting response (throughout a night till the following early morning) [23] than those patients responding to methylphenidate. In addition, parents of the ADHD children tended to prefer nonstimulants to stimulants when the rest is the same otherwise. The nature of such response with atomoxetine and parent preferences for nonstimulants, which were reflected in the utility value survey conducted by Secnik and colleagues [37], led to higher utility values associated with atomoxetine treatment and thereby a greater number of QALYs overall in the context of the economic evaluation.

Overall, the incremental costs per QALYs gained of atomoxetine were between $€ 23323$ and $€ 34$ 308, depending on the patient population. The incremental costs per QALYs gained were consistently lower when atomoxetine was compared to 'no medication', although 'no medication' option was associated with 'zero costs'. This clearly shows that introducing atomoxetine in Spain is beneficial at least for those who are ineligible for methylphenidate treatment as they do not have any treatment alternatives otherwise. Even when compared with methylphenidate (in particular, XR-MPH), atomoxetine as first line therapy was found to be a cost-effective strategy in the treatment of ADHD in Spain [49].

The clinical inputs to the economic model were primarily based on head-to-head randomised clinical trial evidence. Sensitivity analyses confirmed that base case results were likely to be insensitive to changes in input parameters, with the exception of utility values. The utility values appeared to be a key component in determining the costeffectiveness of atomoxetine. However, these utility values were obtained from a robust utility valuation study of ADHD health states [37] that involved parents of children with ADHD as the respondent population and employed standard gamble methodology. In order to minimise any uncertainty or bias surrounding the utility values, the health states descriptors used in the study interviews were 
derived largely based on data from randomised clinical trials and validated by clinical experts [37]. Nevertheless, caution is required when interpreting these utility values since there is no large trial to confirm and validate the health states descriptors. Furthermore, there have been concerns over the use of utilities (and therefore QALYs) for the paediatric population [50]. While ADHD children tend to underestimate their 'disease-specific problems', the validity of utilities elicited with parent proxies has not been fully understood yet [28]. The validation of these utility values is necessary when data become available from sufficiently powered randomised controlled trials.

Several limitations of this study are worth noting. Firstly, our study only considered the drug treatments of ADHD. However, behavioural treatment represents 'a therapeutic mainstay in most European countries' [22,51]. In the recent cost-effectiveness analysis based on the MTA data [52], behavioural treatment was found to be more cost effective than intensive medication management (mainly stimulants) in ADHD children with co-morbid conditions whereas the opposite was true in pure ADHD children (i.e. no co-morbid conditions). The study then suggested behavioural treatment with or without medication as the most cost-effective choice for co-morbid ADHD population. While behavioural treatment is certainly of value, further research to examine the cost-effectiveness of ADHD treatments including nonstimulant atomoxetine remains worthwhile and valuable since stimulants are often contra-indicated for co-morbid conditions. Secondly, patient group involved in the utility survey were those living in the UK and thus their response may differ from those living in Spain. However, as there were no available utility values of treatments for ADHD children in Spain, those utility values used here were the best available data. Thirdly, the perspective of this analysis was that of the National Health Service in Spain and thus only direct medical costs were considered in the model. The exclusion of indirect costs however may be biased against active treatments as effective treatments are likely to decrease these costs. Therefore the estimates of cost-effectiveness of atomoxetine compared to 'no medication' option can be considered conservative. Fourthly, it could be argued that a longer timeframe may be desirable to take into account longer-term differences in costs and adverse effects of treatments. However, any omissions due to the shorter timeframe are likely to be again conservative in that they bias the model generally against the active therapies and more specifically against atomoxetine. For example, the model does not allow for the pattern of care of ADHD patients to change according to response to active therapy. This means the omission of non-drug costs within the model are assumed to be the same across all disease health states. Finally, in an ideal situation it would be preferable to have utility scores estimated from the patient perspective. However, the use of parents of ADHD children as patient proxies is seen to provide the best practical alternative.

\section{Conclusion}

In general, the results of this study showed atomoxetine to be within the bounds of reasonable cost-effectiveness for Spain. In comparison with methylphenidate, atomoxetine as first line therapy appeared as a cost-effective strategy. The additional value offered by atomoxetine was even clearer for those who have no alternative treatment options otherwise. The results of this analysis are considered to be robust, having been based on the best available clinical evidence, expert opinion and a rigorously conducted utility valuation study of ADHD-related health states.

\section{Competing interests}

This study was sponsored by Eli Lilly and company. Jihyung Hong is currently doing her PhD at LSE and also working as a consultant for Eli Lilly and company. Tatiana Dilla and Jorge Arellano are employees of Eli Lilly and Company.

\section{Authors' contributions}

$\mathrm{JH}$ reconstructed the UK economic model for adaptation to the Spanish context, and also wrote this manuscript. TD gave contribution to conception and design and in the critical review of the manuscript. JA, who was one of the contributors for the original UK model, also contributed to a crucial review of this manuscript. All authors read and approved the final manuscript.

\section{Acknowledgements}

We are deeply indebted to Suzi Cottrell, Dominic Tilden, Paul Robinson, Jay Bae, Eric Edgell, Mike Aristides, and Kristina S Boye, for their work in the development of the original UK economic model and the Utility study.

\section{References}

I. Faraone SV, Sergeant J, Gillberg C, Biederman J: The worldwide prevalence of ADHD: is it an American condition? World Psychiatry 2003, 2(2): 104-113.

2. Jensen PS, Garcia JA, Glied S, Crowe M, Foster M, Schlander M, Hinshaw S, Vitiello B, Arnold LE, Elliott G, et al.: Cost-effectiveness of ADHD treatments: findings from the multimodal treatment study of children with ADHD. Am J Psychiatry 2005, 162(9): 1628-1636.

3. Biederman J: Attention-deficit/hyperactivity disorder: a lifespan perspective. J Clin Psychiatry 1998, 59(Suppl 7):4-16.

4. Biederman J, Mick E, Farone SV: Age-dependent decline of symptoms of attention-deficit hyperactivity disorder: impact of remission definition and symptom type. Am J Psychiatry 2000, 157:816-818.

5. American Psychiatric Association: Diagnostic and Statistical Manual of Mental Disorders 4th edition. Washington, DC: American Psychiatric Press; 2000.

6. Kratochvil CJ, Newcorn JH, Arnold E, Duesenberg D, Emslie G, Quintana H, E H, Wagner KD, Gao H, Michelson D, Biederman J: Atomoxetine Alone or Combined With Fluoxetine for Treating ADHD With Comorbid Depressive or Anxiety Symptoms. J AM Acad Adolesc Psychiatry 2005, 44(9):915-924.

7. Banaschewski T, Roessner V, Dittmann RW, Santosh P, Rothenberger A: Non-stimulant medications in the treatment of ADHD. Eur Child Adolesc Psychiatry 2004, I 3 SuppI I: I 02 -II I6. 
8. Downey KK, Stelson FW, Pomerleau OF, Giodani B: Adult attention deficit hyperactivity disorder: psychological test profiles in a clinical population. J Nerv Ment Dis 1997, I 85:32-38.

9. Barkley RA, Guevremont DC, Anastopoulos AD, DuPaul G], Shelton TL: Driving-related risks and outcomes of attention deficit hyperactivity disorder in adolescents and young adults: a 3 to 5-year follow-up survey. Pediatrics 1993, 92(2):2 I 2-2 I8.

10. Mannuzza S, Klein RG, Bonagura N, Malloy P, Giampino TL, Addalli KA: Hyperactive boys almost grown up. V. Replication of psychiatric status. Arch Gen Psychiatry 1991, 48(I):77-83.

II. Mannuzza S, Klein RG, Bessler A, Malloy P, LaPadula M: Adult psychiatric status of hyperactive boys grown up. Am J Psychiatry 1998, I 55(4):493-498.

12. Hart EL, Lahey BB, Loeber R, Applegate B, Frick PJ: Developmental change in attention-deficit hyperactivity disorder in boys: four-year longitudinal study. J Abnorm Child Psychol 1995, 23(6):729-749.

13. Rasmussen P, Gillberg C: Natural outcome of ADHD with developmental coordination disorder at age 22 years: a controlled, longitudinal, community-based study. J Am Acad Child Adolesc Psychiatry 2000, 39(I I): |424-|43I.

14. Harpin VA: The effect of ADHD on the life of an individual, their family, and community from preschool to adult life. Arch Dis Child 2005, 90(SuppI I):i2-7.

15. Alvarez C, Barriento R: Variability and tendencies in the consumption of methylphenidate in Spain. An estimation of the prevalence of attention deficit hyperactivity disorder. Rev Neurol 2003, 37:806-8I0.

16. Garcia-Jimenez MC, Lopez-Pison J, Blasco-Arellano MM: The primary care paediatrician in attention deficit hyperactivity disorder. An approach involving a population study. Rev Neurol 2005, 4 I (2):75-80

17. Cardo E, Servera M, Llobera J: Estimation of the prevalence of attention deficit hyperactivity disorder among the standard population on the island of Majorca. Rev Neurol 2007, 44(I): $10-14$

18. National Institute for Health and Clinical Excellence (NICE): TA98 Methylphenidate, atomoxetine and dexamfetamine for attention deficit hyperactivity disorder (ADHD) in children and adolescents:guidance. [http://wwwniceorguk/Guidance/ TA98/Guidance/pdf/English]. [Accessed July 3I, 2007]

19. Escobar R, Soutullo C, Sebastian S, Fernandez E, Julian I, Lahortiga F: Atomoxetine safety and efficacy in children with attention deficit/hyperactivity disorder (ADHD): initial phase of 10 week treatment in a relapse prevention study with a Spanish sample. Actas Esp Psiquiatr 2005, 33(I):26-32

20. Harpin VA: Medication options when treating children and adolescents with ADHD: interpreting the NICE guidance 2006. Arch Dis Child Educ Pract Ed 2008, 93(2):58-65.

21. King S, Griffin S, Hodges Z, Weatherly H, Asseburg C, Richardson G, Golder S, Taylor E, Drummond M, Riemsma R: A systematicreview and economic model of the effectiveness and cost-effectivenessof methylphenidate, dexamfetamine and atomoxetine for the treatmentof attention deficit hyperactivity disorder in children andadolescents. Health Technol Assess 2006, I 0(23): iii-iv. xiii- 46

22. Schlander M: Health Technology Assessments by the National Institute for Health and Clinical Excellence. A Qualitative Study New York: Springer; 2007.

23. Kelsey DK, Sumner CR, Casat CD: Once-Daily Atomoxetine Treatment for Children With Attention-Deficit/Hyperactivity Disorder, Including an Assessment of Evening and Morning Behavior: A Double-Blind, Placebo-Controlled Trial. Paediatrics 2004, I | 4: I-8.

24. Pelham WE, Gnagy EM, Burrows-Maclean L, Williams A, Fabiano GA, Morrisey SM, Chronis AM, Forehand GL, Nguyen CA, Hoffman MT, et al:: Once-a-day Concerta methylphenidate versus threetimes-daily methylphenidate in laboratory and natural settings. Pediatrics 200I, I 07(6): EI 05.

25. Swanson J, Gupta S, Lam A, Shoulson I, Lerner M, Modi N, Lindemulder E, Wigal S: Development of a new once-a-day formulation of methylphenidate for the treatment of attentiondeficit/hyperactivity disorder: proof-of-concept and proof-ofproduct studies. Arch Gen Psychiatry 2003, 60(2):204-2II.

26. Wolraich ML, Greenhill LL, Pelham W, Swanson J, Wilens T, Palumbo D, Atkins M, McBurnett K, Bukstein O, August G: Randomized, controlled trial of oros methylphenidate once a day in children with attention-deficit/hyperactivity disorder. Pediatrics 200I, 108(4):883-892

27. Cottrell S, Tilden D, Robinson P, Bae J, Arellano J, Edgell E, Aristides M, Boye KS: A Modeled Economic Evaluation ComparingAtomoxetine with Stimulant Therapy in the Treatment of Children withAttention-Deficit/Hyperactivity Disorder in the United Kingdom. Value Health 2008, I I (3):376-388.

28. Brown TE: Emerging Understanding of Attention-Deficit Disorders and Comorbidities in Attention-Deficit Disorders and Comorbidities in Children, Adolescents, and Adult Washington, DC: American Psychiatric Press; 2000.

29. Electronic Medicines Compendium (eMC) [Online]: [http:// www.medicines.org.uk/emc.aspx].

30. Newcorn JH, Zhang S, Rogers AK, Levine LR: Atomoxetine treatment response in ADHD patients naive to previous pharmacotherapy [abstract]. American Academy of Child and Adolescent Psychiatry 5/th Annual Meeting; October 19-24, 2004, Washington DC .

31. Efron D, Jarman F, Barke M: Methylphenidate versus dexamphetamine in children with attention deficit hyperactivity disorder: a double-blind, crossover trial. Pediatrics 1997, I 00(6):E6.

32. TreeAge Software. Inc: TreeAge Software: TreeAge Pro2007. Williamstown MA 2007.

33. Sonnenberg FA, Beck R: Markov Models in Medical Decision Marking: A Practical Guide. Med Decis Making I993, I3:322-338.

34. Base de datos del Medicamentos [Drug database] [http:// www.portalfarma.com/]

35. Concerta TM, (Summary Products Characteristics)[Online]: [https:// sinaem4.agemed.es/consaem/].

36. Rubifen TM, (Summary Products Characteristics)[Online]: [https:// sinaem4.agemed.es/consaem/]

37. Secnik K, Matza LS, Cottrell S, Edgell E, Tilden D, Mannix S: Health state utilities for childhood attention-deficit/hyperactivity disorder based on parent preferences in the United kingdom. Med Decis Making 2005, 25(I):56-70.

38. Michelson D, Faries D, Wernicke J, Kelsey D, Kendrick K, Sallee FR, Spencer T: Atomoxetine in the treatment of children and adolescents with attention-deficit/hyperactivity disorder: a randomized, placebo-controlled, dose-response study. Pediatrics 200I, I08(5):E83.

39. Spencer T, Heiligenstein JH, Biederman J, Faries DE, Kratochvil C], Conners CK, Potter WZ: Results from 2 proof-of-concept, placebo-controlled studies of atomoxetine in children with attention-deficit/hyperactivity disorder. J Clin Psychiatry 2002, 63(I 2): I| I40-II 47

40. Michelson D, Allen AJ, Busner J, Casat C, Dunn D, Kratochvil C, Newcorn J, Sallee FR, Sangal RB, Saylor K, et al.: Once-daily atomoxetine treatment for children and adolescents with attention deficit hyperactivity disorder: a randomized, placebocontrolled study. Am I Psychiatry 2002, I 59(I I): I896-190I.

4I. Kurlan R, Allen AJ, Gilbert D, Linder S, Lewis D, Winner P, Dunn D, Sallee FR, Milton D, Mintz M, et al.: Atomoxetine Treatment In Children With ADHD And Comorbid Tic Disorders. Neurology 2005, 65:1941-1949.

42. Weiss M, Tannock R, Kratochvil C, Dunn D, Velez-Borras J, Thomason $C$, Tamura R, Kelsey D, Stevens L, Allen AJ: A randomized, placebo-controlled study of once-daily atomoxetine in the school setting in children with ADHD. I Am Acad Child Adolesc Psychiatry 2005, 44(7):647-655.

43. Gillberg C, Lothgren M, Fitzgerald P, Cottrell S, Burridge J, Aristides $M$ : Atomoxetine versus methylphenidate as a treatment for ADHD in children and adolescents: A meta-analysis of safety data incorporating active comparator and placebo controlled trials [abstract/poster presentation]. European Society for Child and Adolescent Psychiatry (ESCAP): 28 Sep - I Oct 2003, Paris, France .

44. Schachter HM, Pham B, King J, Langford S, Moher D: How efficacious and safe is short-acting methylphenidate for the treatment of attention-deficit disorder in children and adolescents? A meta-analysis. CMAJ 200I, I65(I I):|475-I488.

45. Bae JP: Meta-regression Analysis of Efficacy in Atomoxetine Randomized Controlled ADHD Trials [Podium presentation]. European International Society of Pharmacoeconomic and Outcomes Research (EISPOR): 6-9 Nov 2004, Florence, Italy. 
46. Kratochvil C], Heiligenstein JH, Dittmann R, Spencer TJ, Biederman J, Wernicke J, Newcorn JH, Casat C, Milton D, Michelson D: Atomoxetine and methylphenidate treatment in children with ADHD: a prospective, randomized, open-label trial. J $\mathrm{Am}$ Acad Child Adolesc Psychiatry 2002, 4 I (7):776-784.

47. Newcorn JH, Kratochvil CJ, Allen AJ, Casat CD, Ruff DD, Moore RJ, Michelson D: Atomoxetine and osmotically released methylphenidate for the treatment of attention deficit hyperactivity disorder: acute comparison and differential response. Am J Psychiatry 2008, 165(6):72I-730.

48. Michelson D, Buitelaar JK, Danckaerts M, Gillberg C, Spencer TJ, Zuddas A, Faries DE, Zhang S, Biederman J: Relapse prevention in pediatric patients with ADHD treated with atomoxetine: a randomized, double-blind, placebo-controlled study. J Am Acad Child Adolesc Psychiatry 2004, 43(7):896-904.

49. Sacristán JA, Oliva J, Del Llano J, Prieto L, Pinto JL: What is an efficient health technology in Spain? Gac Sanit 2002, 16:334-343.

50. Schlander M: Long-acting medications for the hyperkinetic disorders. A note on cost-effectiveness. Eur Child Adolesc Psychiatry 2007, I 6(7):42I-429.

5I. Taylor E, Dopfner M, Sergeant J, Asherson P, Banaschewski T, Buitelaar J, Coghill D, Danckaerts M, Rothenberger A, Sonuga-Barke E, et al.: European clinical guidelines for hyperkinetic disorder first upgrade. Eur Child Adolesc Psychiatry 2004, I 3(Suppl I):17-30.

52. Foster EM, Jensen PS, Schlander M, Pelham WE Jr, Hechtman L, Arnold LE, Swanson JM, Wigal T: Treatment for ADHD: is more complex treatment cost-effective for more complex cases? Health Serv Res 2007, 42(I Pt I): 165-182.

\section{Pre-publication history}

The pre-publication history for this paper can be accessed here:

http://www.biomedcentral.com/1471-244X/9/15/pre

pub

Publish with Biomed Central and every scientist can read your work free of charge

"BioMed Central will be the most significant development for disseminating the results of biomedical research in our lifetime. "

Sir Paul Nurse, Cancer Research UK

Your research papers will be:

- available free of charge to the entire biomedical community

- peer reviewed and published immediately upon acceptance

- cited in PubMed and archived on PubMed Central

- yours - you keep the copyright
BioMedcentral 